\title{
Perfectly Reasonable in a Practical World: Understanding Chemistry Teacher Responses to a Change Proposal
}

\author{
Hanna Westbroek ${ }^{1}$ (D) Fred Janssen ${ }^{2} \cdot$ Walter Doyle $^{3}$ \\ Published online: 17 October 2016 \\ (C) The Author(s) 2016. This article is published with open access at Springerlink.com
}

\begin{abstract}
Curriculum ideals often get compromised as a curriculum moves through its various levels of representation. Across the different science reforms, this process of slippage is clearly present. Research shows that teacher subject matter knowledge, PCK, beliefs and context factors all influence implementation. Professional development arrangements focus on fixing deficiencies in teachers' knowledge, beliefs or work context. This approach has not solved the problem of slippage, as we still do not understand what mechanisms operate when teachers make decisions about change proposals. In this study, we unpacked the decision mechanisms of three highly qualified chemistry teachers who subsequently adapted an innovative contextbased chemistry unit. In spite of a state of the art professional development arrangement and the teachers being highly qualified, slippage occurred. The teachers' goal systems were used to interpret their reasoning. A goal system is a context-dependent, within-person mental construct that consists of a hierarchy of a person's goals and means in pursuit of a task. We showed that all three teachers adopted or redesigned elements of the change proposals to meet their core goals, i.e., goals that had multiple connections with other goals. This indicated that the adaptations teachers made were perfectly reasonable ways to serve their professional goals. For change to happen, we contend that one should begin with ways to connect teachers' core goals with the lesson or unit goal demands of a proposed innovation. Change emerges from the adaptions teachers make in the service of their core goals.
\end{abstract}

Keywords Curriculum innovation · Curriculum slippage · Practical reasoning · Goal system theory $\cdot$ Core goals

Hanna Westbroek

H.B.Westbroek@vu.nl

1 Faculty of Psychology and Pedagogy, VU University Amsterdam, Van der Boechorststraat 1, 1081 BT Amsterdam, The Netherlands

2 ICLON, Willem Einthoven Gebouw, Leiden University Graduate School of Teaching, Wassenaarseweg 62A, Leiden 2333 AL, The Netherlands

3 The University of Arizona, 1430 E. Second Street, Tucson, AZ 85721, USA 


\section{Introduction}

Research has substantially advanced our understanding of the processes of knowledge and skill acquisition in science education (Abell and Lederman 2007). However, school practices have not been innovated and improved in ways that reflect this progress in understanding. Science education reformers, for example, regularly promote teaching for understanding in which teachers and pupils engage in discourse about important ideas and participate in problem-solving activities grounded in meaningful contexts (Aikenhead 2003; Kloser 2014; Millar and Osborne 1998). In spite of this, large-scale classroom studies show that the dominant teaching practice in science (and other subject areas) is still based on a presentation view of teaching and a rehearsal and application view of learning (Gage 2009; Lyons 2006).

Goodlad (1979) argued that the problem of the low impact of curriculum reform could be seen as "slippage" which occurs when ideals are compromised as a curriculum moves through its various levels of representation. Ideas and design principles are translated into concrete materials, which are interpreted and implemented by teachers, which, in turn, induce a range of learning experiences for their pupils (Goodlad 1979; Remillard and Heck 2014; Van den Akker 2010). The successive design processes that occur when intentions are transformed into classroom practice often involve adaptations. Such adaptations are not, in themselves, problematic - a set of principles can be expressed in several forms - except when these modifications result in a loss (slippage) of the initial innovative ideals (e.g., Doyle and Ponder 1977; McDonald 2003; Remillard 2005).

Across the different science reform movements that have emerged over the past decades, this process of slippage is clearly present. One longstanding goal of several science curriculum reforms is, for example, that students develop informed conceptions about the nature of science (NOS) by experiencing authentic scientific inquiry (Abd-ElKhalick 2012; Edelson 2001; Krajcik et al. 2001). However, the impact of reform in this domain has been disappointing (Abd-El-Khalick 2012; Lederman 2007; Hofstein and Lunetta 2004). The same can be said of the Science, Technology, Society (STS) movement, which arose from the desired need to make science education more relevant to all students by emphasizing the role of science in society and involving students in STS decision-making (e.g., Pedretti and Nazir 2011; Solomon 2003; Zeidler et al. 2005). Although many context-based science curriculum reforms have emerged from this movement (Gilbert 2006), including the Dutch context-based chemistry curriculum reform discussed in this paper, their impact on actual science teaching practice is still relatively low (Pea and Collins 2008; Pedretti and Nazir 2011; Vos 2010).

Much research has been done around the question why this is the case. An important part of this research specifically focusses on the role of the teacher. We know, for example, that subject matter knowledge and knowledge about how to teach that subject matter (pedagogical content knowledge) are important and, when lacking can impede successful implementation of reforms (Bartos and Lederman 2014; Charalambous and Hill 2012; Van Driel and Berry 2012). Moreover, teachers' beliefs about teaching and learning can conflict with the reform and this can influence implementation (Tobin and McRobbie 1996; Pintó 2005; Roehrig et al. 2007). Additionally, other factors can highly influence teachers' reactions to a change proposal, such as, exams, perceptions of the needs of students, levels of local support for implementation, perceptions of time and effort required for implementation, and perceptions of the extent to which the change proposal deviates from regular practice (e.g., Kennedy 2010; Ryder and Banner 2013; Spillane et al. 2002). 
Although we know that a teacher's knowledge, beliefs and perception of context factors all influence implementation of change proposals (Borko et al. 2010; Van Veen et al. 2010), we still do not know how all these factors interact and influence decisions teachers make in a specific context in pursuit of a task. Teachers can, for example, enact the same text books quite differently (e.g., Otten and Soria 2014; Thomson and Senk 2014). Sometimes teachers seem to act according to their knowledge and beliefs and sometimes not (e.g., Kennedy 2010; Forbes 2013; Mathijsen 2006). Furthermore, sometimes teachers implement change proposals in spite of seemingly impeding context factors and sometimes not (e.g., Datnow and Castellano 2000). We do not know why this is the case, that is: what mediates between a teacher's knowledge, beliefs and perceptions of context factors and his or her decisions about a specific task. We lack theory that connects a teacher's knowledge, beliefs and perception of context factors to situated action (Borko et al. 2008; Forbes 2013). The result is that it is still difficult to target professional development trajectories to specific decision-making processes of teachers.

In this paper we argue that goals play an important mediating role between knowledge, beliefs and context demands (Schoenfeld 2011). Goals can be seen as internally represented desired states or standards and have proved to be the most proximate determinant for action (Carver 2012; Lord et al. 2010) as they mediate the effects of both context and knowledge/ beliefs (Fishbach and Ferguson 2007; Fishbein and Ajzen 2010; Smedslund 2012). The question remains of course, how goals direct (planning of) actions. This process is one of the main focuses of research on goal systems and self-regulation in social and personality psychology (Vohs and Baumeister 2011).

In this paper we argue therefore that goal system theory and self-regulation theory can contribute to a better understanding of the continuing experience of slippage between innovation and practice and what mechanisms operate when teachers make decisions about adapting change proposals, even in state of the art professional development settings. Our argument is grounded in the analysis of the decision mechanisms of three highly qualified chemistry teachers who adapted an innovative context-based chemistry unit. In all three cases we show how teachers' goal systems (Shah and Kruglanski 2008) can serve as a frame for deeper understanding of teacher responses to an innovation. By understanding slippage under ideal conditions, we hoped to better understand how and why slippage takes place and, perhaps, construct a more complete and urgently needed process model of how innovate designs connect to teaching practice.

\section{Goal System Theory and Self-Regulation Theory}

As we pointed out in the introduction, goals can be seen as internally represented desired states or standards and have proved to be the most proximate determinant for action as they mediate the effects of both context and knowledge/beliefs (Carver 2012; Fishbein and Ajzen 2010; Smedslund 2012). In complex practical work environments - such as teaching - people typically strive for multiple goals simultaneously that are difficult to weight comparatively. For example, teachers do not solely strive to facilitate student learning; they also need to cover content in time, maintain lesson momentum, etc. (e.g., Kennedy 2010) within limited time, and with limited resources and capacity (Simon 1956, 1996). In these types of complex situations people strive for reasonable rather than optimal realization of goals (Pollock 2006). We are simply not able to weigh outcomes of all possible alternative acts (lower goals) and calculate 
what act would lead to the optimal outcome (Simon 1996). Subsequently, the goals that people connect to their actions can typically reflect both more fundamental beliefs (e.g., students need to become actively involved in order to increase their understanding of certain concepts) and context demands (e.g., cover content in time).

The common thread across theories of self-regulation is that individuals set goals, compare progress against the goals, and make modifications to their behaviors and or cognitions to attain their goals (Carver and Scheier 2011; Austin and Vancouver 1996; Shah and Kruglanski 2008).

How goals are connected to actions is represented in a goal system. A goal system is a context-dependent within-person mental construct that consists of a hierarchy of goals and means in pursuit of a task (Shah and Kruglanski 2008). Someone might connect a higher goal (e.g., "maintain work order") to several different lower goals when planning a lesson (e.g., start the lesson with greeting the students; give turns in class discussion) in a certain context. Also, someone might connect his/her lower goals (e.g., start the lesson with greeting the students) to several higher goals (establish a relation with students, maintain work order). Not all goals in a goal system are equally important for people. Kruglanski et al. (2012) distinguish two important structural features in this respect: (1) multifinality-when goals serve many other higher goals; and (2) equifinality - when a goal is served by many lower goals. Kruglanski et al. (2012) observed that people value goals with these types of connection more than goals with fewer connections. Following Wieringa et al. (2013) we will refer to goals with more than one connection as core goals.

The higher that goals are situated in the hierarchy of someone's goal system, the more abstract and the more long-term they are. Such goals reflect being in particular ways (Carver 2012). Higher goals in a teacher's goal system can, for example, reflect aspects of the kind of teacher one wants to be (e.g., a teacher who shows students that chemistry is everywhere around them) and principles that connect to those aspects (e.g., instill wonder among students about scientific phenomena). The lower in the hierarchy, the more concrete and short-term actions the goals reflect. Lower goals are the means to achieve higher goals. A "do-goal" that a teacher might connect to the principle goal "instill wonder" could for example be "show a demo-experiment of an intriguing scientific phenomenon." Still lower might be the motoric do-goal "light the Bunsen burner," that involves merely automated routine acts that may take seconds.

Goal systems evolve as people continuously compare results of actions to the goals they have set. Discrepancies can lead to behavioral changes or changes in the interpretation of goals. In self-regulation theory, this is referred to as the negative-feedback loop (Lord et al. 2010). Note that in a complex practical work environment, people can never do this in an optimal way. In the case of a curriculum innovation proposal, a teacher will always estimate (instead of determine) to what extent he/she considers the change proposal an improvement to his/her regular practice, with respect to all the goals he/she is aiming at.

How a person sets and evaluates goals is also time dependent. Higher goals are typically stable. A negative-feedback loop to evaluate whether lower goals contribute to "particular ways of being" and whether those ways of being should be reinterpreted typically takes years. Whereas negative-feedback loops to evaluate whether certain specific actions contribute to keeping order might take minutes, hours or days to change (Lord et al. 2010).

Next, we describe the study we conducted and how we used goal system theory to interpret the adaptations three highly qualified chemistry teachers made to a context-based organic chemistry unit. In the section Co-construction of a teacher's goal system representation we 
explain how we used goal system theory to co-construct with the teachers their goal system representation of the task at hand.

\section{The Study}

The study concerns a typical case of curriculum slippage. Three highly qualified Dutch chemistry teachers participated in a state of the art professional development trajectory that aimed at implementing a new context-based chemistry curriculum. All three teachers attempted to enact an innovative context-based organic chemistry unit that aimed at 15-16year-old pre A-level students. In the adapted versions of the unit that the teachers actually enacted, the key ideas of the innovation were typically all lost. These results are consistent to what we already know about curriculum enactment and do not contribute fundamentally new insights about the process, let alone provide clues for designing effective professional development.

This study therefore focussed on understanding better the "reasonableness" of the teachers' decisions about adapting the innovative unit to their particular circumstances. We thought that such an analysis might locate the points at which slippage occurred which, ultimately, could provide grounded insights into possible ways to redirect enactment to preserve the key ideas of the innovation. Concretely our research question was how can we understand teacher responses to a context-based chemistry unit in terms of serving their core goals?

To conduct this analysis of the dynamics of slippage, we co-constructed with these teachers their respective goal system representations of how they regularly taught a unit and identified what were their core goals. As will be seen, these goal systems functioned as an explanatory frame: the adaptations the teachers made to this particular innovative unit became reasonable and predictable from the teacher's perspective.

\section{The Dutch Context-Based Chemistry Reform Initiative}

The present study took place within the context of the Dutch Context-Based Chemistry (CBC) reform effort and, in particular, the design phase of that effort aimed at transforming the principles of the reform into a curriculum that would be implemented in classrooms. The Dutch chemistry reform committee established general principles of context-based chemistry, inspired by the German reform Chemi im Kontext (Parchmann et al. 2006; Vos 2010). The particular unit selected for this study was designed for pre A-level students (15-16-year-old students) and was constructed according to CBC principles by curriculum designers/ researchers that were part of the original group that initiated the reform.

The national reform was initiated in response to the many problems that were attributed to the regular curriculum, which was considered to be overloaded, focused on the learning of isolated facts, and not very relevant to students (Driessen and Meinema 2003; Gilbert 2006). Students considered chemistry rather abstract and difficult and most students did not opt for science or chemistry studies after secondary education. A case was made that using contexts as a starting point for the development of chemical knowledge and skills would contribute to solving these problems and to meaningful learning processes (Bennett et al. 2007; Gilbert 2006). Context-oriented curricula units start with chemical practices (the contexts), and then chemical concepts, theories, and skills are introduced on a need-to-know basis. This implies that contexts become the primary guiding principle for selecting and structuring the content of 
school chemistry (a context-led development of concepts), instead of the conceptual structure of current school chemistry (Gilbert 2006). Contexts might vary from application practices such as "production and use of smart materials" to practices that have a more scientific inquiry character (e.g., modeling processes). Curriculum designers used real-life practices and problems as inspiration for the development of units. Goals and goal-oriented activities and procedures were derived from such real-life practices (e.g., determine whether the water quality of a certain water body meets the norms for its use) and formed the base for designing context-based units (e.g., Westbroek et al. 2010; Prins et al. 2008). This way a more processoriented emphasis on how chemical knowledge is applied or produced broadened the emphasis in chemistry education on developing a solid knowledge base (cf. Roberts 1988).

Another aspect of the reform emphasized that students also should become more actively involved than is typically the case in learning chemistry by having increased opportunities to take control and responsibility for their own learning processes through self-regulating activities (Parchmann et al. 2006). Active involvement and self-regulation were seen as ways to enhance both understanding and motivation for learning chemistry (Boekaerts et al. 2000; Deci and Ryan 2000).

These theoretical notions resulted in general principles for structuring context-based chemistry units within the Dutch chemistry curriculum reform. Figure 1 presents the fundamental $\mathrm{CBC}$ principles of real-world contexts and self-regulated involvement as a flow of phases and unit goals ("do goals") within phases. Each unit started with an introduction phase that consisted of an orientation on the context on a phenomenon level, followed by an orientation on the context on a molecular level. Student autonomy was fostered in the next phases"curiosity and planning" and "elaboration" - by engaging them in self-regulating activities. During these phases, students, with coaching from the teacher, developed their own questions (context driven questions), developed and carried out work plans and presented their results (the planning and carrying out experiments goals respectively). This process was intended to result in a deeper understanding of the context and its chemical foundation. In the "deepening and connecting" phase, the teacher extended the context further by broadening the chemical knowledge base and by making connections to other contexts (Explaining chemical concepts goal and connections to other contexts and domains goal). In this phase the emphasis was on transfer of learning outcomes. The unit concluded with a test or unit assignment to assess learning.

\section{Teacher-Design Teams}

In 2003, teacher-design teams were established to transform the context-based chemistry rationale and design principles (Driessen and Meinema 2003) into detailed curriculum units. These units were to function as exemplary materials for other chemistry teachers (cf. Davis and Krajcik 2005). The first version of the curriculum was created by designers/researchers that

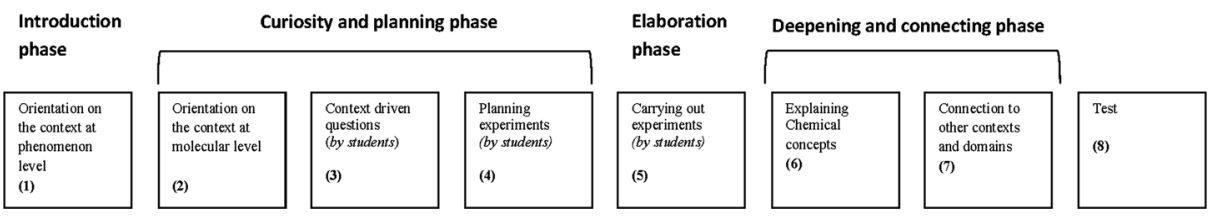

Fig. 1 Representation of a context-based chemistry unit as a flow of unit goals 
were part of the group that took the initiative for this reform and was intended to reflect closely the context-based chemistry design principles of Fig. 1.

Subsequent to this initial design work, other teacher design teams, often coached by an expert in the innovation, started around 2010 to refine the units. Units were disseminated as Word documents to enable teachers to further adapt them to their situations. The premise of the project was that a collaborative design process of moving from a conceptual idea to a product — analogous to design tasks in practice-based disciplines (Naidu et al. 2000)—would enhance implementation, as professional development and curriculum design and implementation processes were expected to become intertwined (Borko 2004; Könings et al. 2005; Parchmann et al. 2006). In fact, in this state of the art professional development arrangement, teachers were expected to produce teaching methods that were both in accordance with the core ideas of the proposed innovation and feasible for their practice. Such processes involved design decisions based on certain expectations and on an evaluation of how the design actually functioned in the practice of the classroom. Additionally, collaboration in teacher design teams was expected to create opportunities for reflection on learning processes and new teaching experiences (Little 2002; Borko 2004; Lumpe 2007; Voogt et al. 2011). At the time of the current study, several versions of the curriculum had been generated through this process.

\section{Sample}

The study we present was part of a broader study on teacher design teams (TDTs), design processes and teacher learning. Different TDTs worked on different context-based units. We found that all TDTs adapted units and that curriculum slippage was common. In order to further unpack and compare individual decision-making mechanisms underlying slippage, we decided to "follow" the redesign and implementation path of one particular unit. We selected three teachers of two TDTs who subsequently redesigned and enacted the particular contextbased unit. All three teachers were deeply involved in and committed to the design processes. That is, they had the knowledge and beliefs necessary to be model adopters.

The first teacher for this study was selected because he adapted with his colleague from the same school the original unit (version 1) to create version 2. Teacher 1 had more than 20 years of teaching experience, was very active in selecting, adapting, and enacting CBC units, and he had previously implemented other units from this curriculum. The second teacher in this study took part in a TDT that choose to make further adaptations to version 2 in a later stage of the reform. Teacher 2 eventually implemented version 3 of the curriculum and also had more than 20 years of teaching experience. This was teacher 2's first experience with adapting and enacting a context-based chemistry unit. The third teacher for this study joined the same TDT but only in the final phase of the team activities and not as a co-designer. This teacher had about 5 years of teaching experience and joined to become familiar with the materials as an end user and was interested in exploring the usefulness of the materials for her teaching practice. After joining, the third teacher chose to further adapt version 3 to create and implement version 4.

\section{Data Collection and Analysis}

The teachers were each interviewed for 1.5 to 2 hours. The interviews and the analysis of the responses were framed within a methodology drawn from the goal system theory (as described below). The teacher interviews were designed to: 
1. Elicit the teachers' goal systems (GS) of teaching a unit to provide insight into each teacher's decision mechanism. These goal system representations revealed each teacher's perception of the task in terms of sequences of unit goals and the goals they connected to each of these goals (see description below). The goal system representations enabled us to establish for each teacher what his/her core goals were and to which other higher and/or lower core goals they were connected.

2. Identify the adaptations each of the teachers made to the materials. Each teacher was asked how he/she adapted the $\mathrm{CBC}$ unit on organic chemistry for implementation. Together, the teacher and the researcher (first author) worked through the instructional materials while the teacher pointed out the precise adaptations he/she made. Each new version of the CBC unit that was created this way was represented as a flow of unit goals, similar to the level of description in their goal systems by the first author. The representations were checked by the respective teacher (see Fig. 2 for an overview). The flow of unit goals of the original version of the $\mathrm{CBC}$ unit, and of the version that each teacher created were represented as text boxes (Fig. 2) at the same level of description as the flow of unit goals in their goal systems. Both original and adapted versions were compared to their regular flow of unit goals in the teachers' goal system representations so that it could be established to what extent adaptations could be understood as decisions geared at serving core goals better or avoiding undermining core goals. Analyses were conducted by the first author and checked by the second and third author.

3. Compare results of 1 with 2 to investigate the explanatory power of the teacher's goal systems. Both the original $\mathrm{CBC}$ version and the version created by the respective teacher

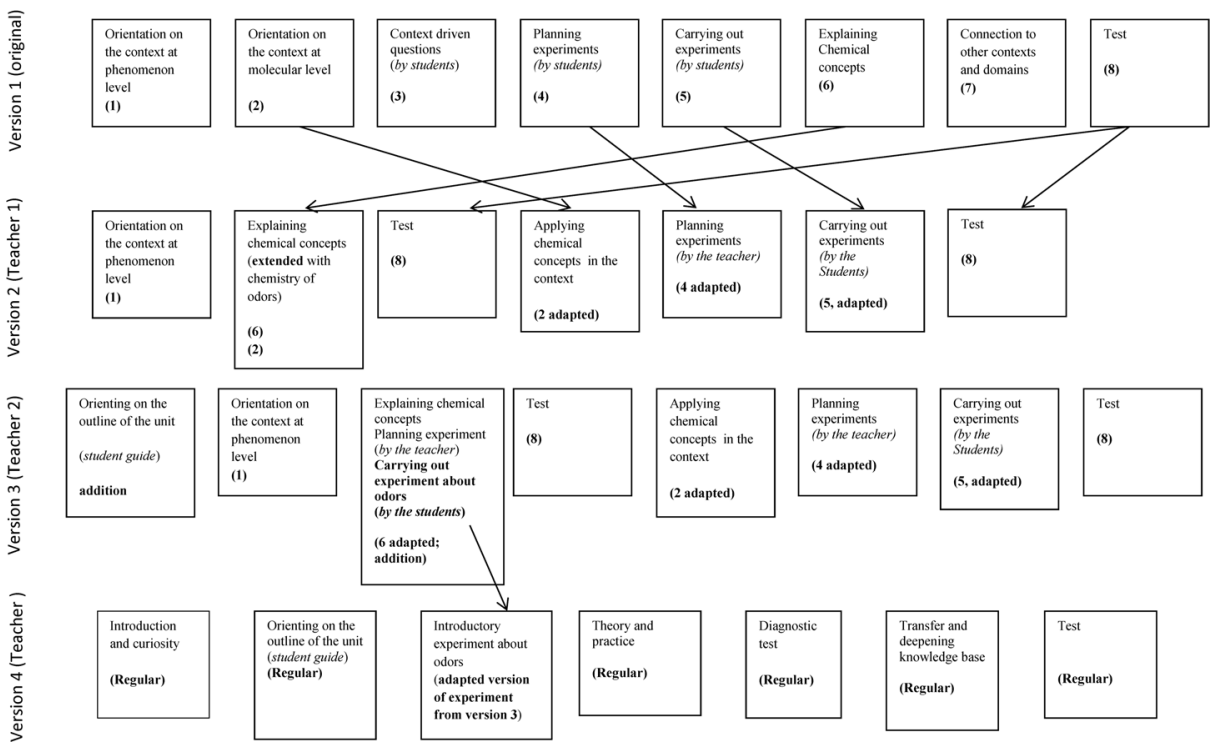

Fig. 2 An overview of the adaptations the teachers made to the original CBC unit and the versions they created. The representations of the different versions of the unit were made by the first author and checked by the teachers. The goals of the original unit are numbered. Sometimes a teacher left out unit goals (e.g., three contextdriven questions by students were left out by all three teachers). The arrows show how unit goals were recombined by a teacher. If extensions, adaptations or additions were made to the original version of the unit goal this is indicated in bold. Teacher 1 made de most rigorous changes, Teacher 2 adopted version 2 and Teacher 3 implemented mostly her regular unit goals which are also indicated in bold 
were compared to the flow of unit goals in the teacher's GS. It was established to what extent both versions could be considered to serve his/her core goals in order to determine whether adaptations could be explained this way.

\section{Co-construction of a Teacher's Goal System Representation}

To construct the teacher's goal system representation, we adapted the widely used and well known laddering method (Grunert and Grunert 1995; Veledo-de Oliviera et al. 2006) for coconstructing the teacher's goal system (Janssen et al. 2013). The laddering method, which originated in clinical psychology, is a well-established procedure in several fields for constructing personal goal-means structures to predict and influence behavior (Little and Travis 2007; Reynolds and Olson 2001) and has been previously used to construct a teacher's GS for teaching a lesson (Janssen et al. 2013, 2014a). In case 1, however, we were interested in the teacher's goal system for the task of teaching a unit. The procedure consists of the following procedure:

1. First, each teacher was asked to picture a unit and a regular class they would teach that unit to and to think about how they would typically teach that unit to students of that particular level.

2. Next, each teacher was asked the following questions: "What do you do when teaching such a unit? What do you regularly start with? What do you typically do next?" (and so on) and to describe briefly each of the unit goals on separate post-its. This way each teacher created a visual representation of his/her sequence of unit goals in response to the researcher's questions. See for example Fig. 3 for teacher 1's flow of unit goals (boxes at the bottom of the GS).

3. Next, for each unit goal the teacher was asked why s/he did things in this way and why s/ he considered this particular goal important. Each of these goal statements were written on separate post-its and placed above the respective unit goal(s). The teachers were also asked to connect the goal statements with the respective unit goal(s) by drawing lines. This way, the teachers extended their visual representation of their sequence of unit goals with the goals they connected to them (e.g., the "what" and "why" of Fig. 3). Furthermore, for each of the goals, the teacher was asked why s/he considered the goal important and this question was repeated until the teacher could not come up with yet a higher goal. The teacher was asked to describe briefly each of these higher goals on separate post-its and to link them with lines to the lower goal(s). For example, the teacher who started every unit with a remarkable phenomenon that students were to explore through experiments did this because he wanted students to be amazed and to raise questions about the phenomenon. In turn, he considered creating amazement and making students formulate questions about a phenomenon important because it served his higher goal that chemistry should be made meaningful for them. This goal, in turn, served his yet higher goal that students ought to learn that "chemistry is everywhere around them."

4. Finally, the teacher was asked to evaluate and validate his/her GS representation. Were goals missing that need to be added? Were goals adequately connected to other goals and to the unit goals (middle goals in the language of the goal system theory)? Were there connections missing that need to be drawn? 
The laddering method resulted in a visual representation of each teacher's goal system, i.e., each teacher's perception of the "what" and "why" of teaching a unit (see for example Fig. 3). Core goals were identified as goals that are connected to multiple other goals (grey in the teachers' goal system representations).

Next, the results are discussed.

\section{Results}

First, Fig. 2 provides an overview of the changes the teachers subsequently made to the original CBC unit. Then, for each teacher the results of the laddering interview are presented: the goal system representation, its description and the identification of core goals. Additionally, the adaptations each teacher made to the CBC unit are discussed. Finally, we present for each teacher the results of our comparison of the original and the adapted version of the CBC unit, with the flow of unit goals in their respective goal system and specifically the results of our analysis with respect to the extent in which results of design decisions can be seen as contributing to or at least not undermining their core goals.

\section{Teacher 1}

\section{Teacher 1's Goal System}

Figure 3 depicts the goal system representation teacher 1 constructed and validated in response to the laddering interview questions. The goal system showed that teacher 1 , in order to make chemistry meaningful to students, regularly started with a phenomenon or context that instilled wonder in students. The higher goal teacher 3 hoped to achieve was that his students would

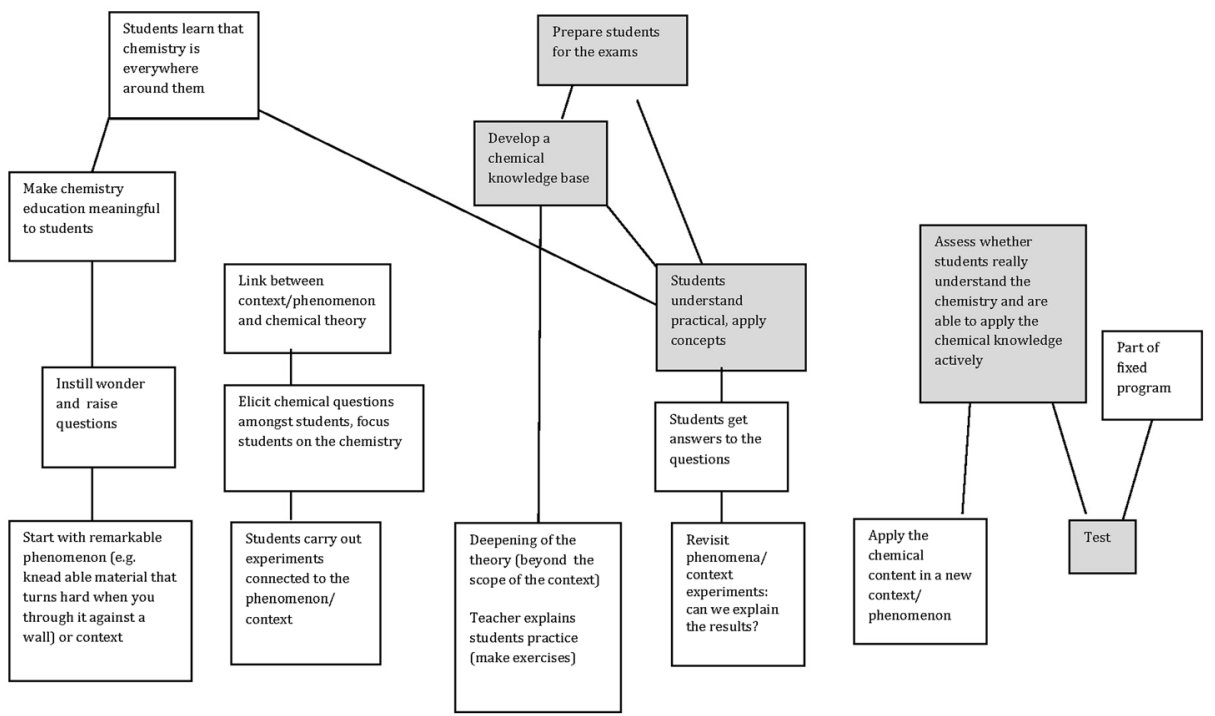

Fig. 3 Teacher 1's goal system of teaching a regular unit. Core goals are marked grey 
have the experience that chemistry is everywhere, a core goal as it is connected to two other lower goals. Next, he used experiments to explore the phenomenon to raise chemical questions that were to be answered later on in the unit. Teacher 1 considered this goal important because it focused students on the chemical content of the unit and it linked the context/phenomenon to chemical theory. In the next goal, called deepening of theory, teacher 1 wanted students to develop a chemical knowledge base ${ }^{1}$, building up knowledge from simple to complex, a goal that he linked to his goal of preparing students properly for the exams. Teacher 1 explained that he felt that students needed a solid conceptual knowledge base to achieve the curriculum attainment targets. In the next goal, the experiments from goal 2 were revisited and students were asked to answer the questions raised in light of their deepened knowledge base. This application of concepts was intended to contribute further to the students' understanding of the chemistry involved and therefore to extend their knowledge of chemistry. Additionally it was intended to contribute to students learning that chemistry is everywhere. Also, this was to contribute to preparing them for the exams properly. The goals-students experience that chemistry is everywhere; develop a chemical knowledge base; students understand practical, apply concepts; prepare students for the exams - all connect to multiple other lower and/or higher goals and can therefore be considered core goals.

The last two goals, apply chemical knowledge in a new context and test, were both employed to assess whether students really understood the chemistry and were able to apply the chemical knowledge actively. The teacher was also committed to the test because it was part of the fixed test program that teachers of each subject were to establish and publish at the start of the school year. Therefore, both the goal assess whether students really understood the chemistry and final test (a "do-goal" in the language of goal system theory) could also be considered core goals as they both connect to multiple other goals.

\section{Adaptations Teacher 1 Made to the CBC Unit}

Teacher 1 made substantial changes to version 1 of the unit (see Fig. 2).

He kept the orientation on the context of odors and perfumes on a phenomenon level goal (unit goal 1 in the original version), but moved the orientation on the context of odors and perfumes on a molecular level (unit goal 2 in the original version) until after the explain chemical concepts goal (unit goal 6 in the original version), and adapted it to create a more simplified apply chemical concepts in the context goal (unit goal 2, adapted) that involved an assignment about the chemistry of different types of odors. Also the selfregulating activities in which students were to develop their own questions about odors and the chemistry of odors and plan their own experiments, that were meant to foster student autonomy in the unit (goals 3-5 in the original version of the unit), were converted by teacher 1 into cookbook practicals that concerned the synthesis of different esters (odors) (in version 2: the planning experiments (by the teacher) (four adapted) goal), and moved until after the explain chemical concepts goal.

Moreover, teacher 1 moved the explain chemical concepts goal (unit goal 6 in the original version) to the front, and adapted it to make it resemble the way the basis of organic chemistry was usually taught: starting with the chemistry and names of simple organic compounds and moving to more complex compounds and basic synthesis reactions that form more complex

\footnotetext{
${ }^{1}$ Co-constructing their goal systems, all teachers used their own terms to describe their unit goals and goals. Teacher 1 recognized that his deepening theory goal coincides with explain theory goal.
} 
compounds. He did add explanations about the chemistry of odors and perfumes (as examples of more complex compounds) and how they can be synthesized to this unit goal in order to make it fit the context. Teacher 1 also added a diagnostic test goal (unit goal 8 in the original version) between the explain theory goal and the applying chemical concepts in the context goal (adapted version of the original unit goal 2).

\section{Using Teacher 1's Goal System as an Explanatory Frame}

Teacher 1 did implement aspects of the $\mathrm{CBC}$ unit, elements of the context odors and perfumes are clearly present, but essentially created a CBC unit version in which the chemical concepts were developed in a classical way, rather than using the context as a guiding principle to select and structure chemical concepts on a need-to-know basis (see Fig. 2). If we look at Fig. 3, this can be explained by means of teacher 1's interconnected core goals: students develop a chemical knowledge base, students understand practical by applying concepts they learned. Apparently teacher 1 considered these core goals that he mostly operationalized in a traditional way in the deepening of the theory goal (building up knowledge from simple to complex). Teacher 1 adapted and/or removed every unit goal of the original version that can be seen as undermining these goals (e.g., letting students investigate their own questions; start with complex chemistry of odors instead of building up knowledge from simple to complex). Second, the new aspects inspired by the $\mathrm{CBC}$ unit that teacher 1 did implement -orientation to the phenomenon of odors and perfumes, the chemistry of odors at the end of his deepening of the theory goal, the application task about odors and the practicals about esters - can be seen as fitting other core goals of teacher: after developing a chemical knowledge base, students revisited the context (odors) and applied their knowledge in an application task about odors and a cookbook practical about making odors. Both these new goals can be seen as elaborations of goals in teacher 1's goal system (see Figs. 2 and 3), namely the goal revisit phenomena...(that contributed to his core goals student understand practical and apply concepts that in turn was connected to other core goals of teacher 1) and the goal apply chemical knowledge in new context (that contributed to his core goal to assess whether students really understood the rather complex chemistry etc.).

Finally, the fact that teacher 1 included a diagnostic test about the chemical knowledge base can also be explained as a means to achieve the core goal assess whether students really understand the chemistry etc.

\section{Teacher 2}

\section{Teacher 2's Goal System}

Figure 4 presents Teacher 2's goal system representation for teaching a regular unit. Teacher 2 regularly started a unit by providing students with a study guide: an overview of the unit and planning (including tests), the prior knowledge they needed, and diagnostic tests and differentiating assignments that they could work on independently. Teacher 2's GS shows that he connected this goal to several different reasons: it helped him prepare for teaching the unit, it contributed to synchronization between colleagues, it contributed to his goal that students learned to work independently and it provided students support, clarity and structure (about prior knowledge, what the unit was about, when the tests were, etc.). The study guide can therefore be seen as a core goal of teacher 2 . 


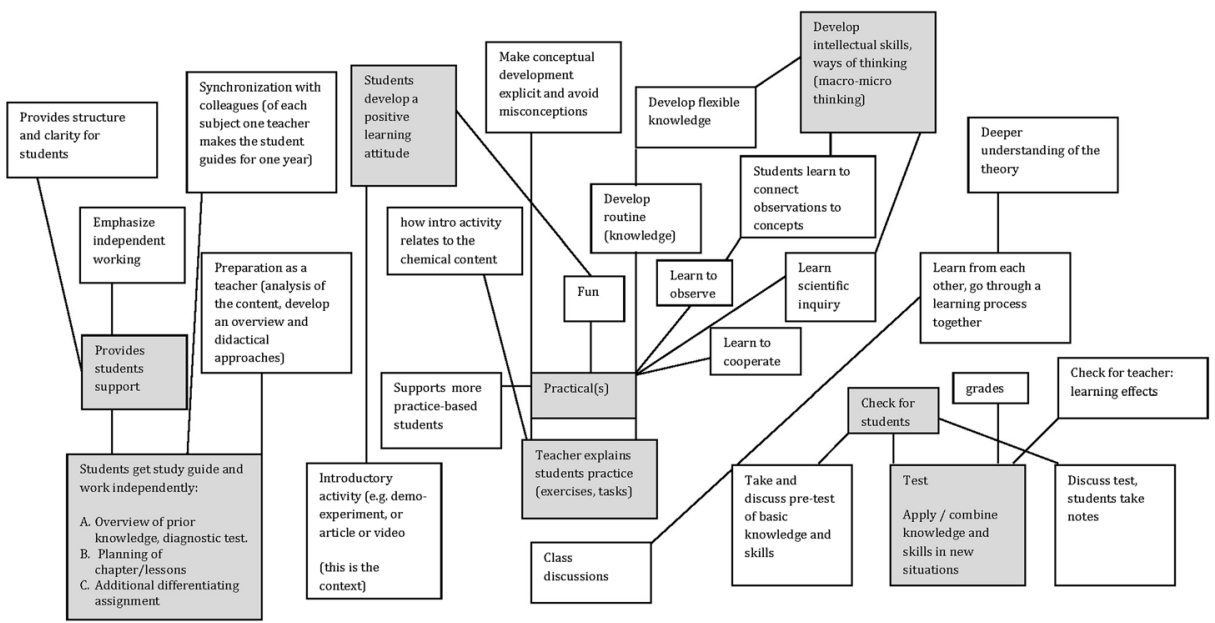

Fig. 4 Teacher 2's goal system of teaching a regular unit. Core goals are marked grey

Next, he typically carried out an introductory activity, as he expected that this contributed to a positive learning attitude toward the particular unit. The main part of the unit consisted of teacher 2 explaining new theory while students practice, which he alternated with practical work and class discussions. Practical work was a core goal of Teacher 2 as he considered this important for several reasons: it was fun and therefore contributed to a positive learning attitude. Together with the explaining and practicing goal (also a core goal of T2), practical work helped students develop routine and therefore flexible knowledge. According to teacher 2 practical work also contributed to the goal that students learned to observe, which in turn was connected to his goal that students connected observations to concepts. A related goal served by practical work was that students learned about scientific inquiry. All this, according to teacher 2, contributed to his goal that students developed intellectual ways of chemical thinking (e.g., macro-micro thinking, a core goal in itself). Another reason that teacher 2 implemented practical work was that it supported students who were more practice-based (learned by doing). Finally, teacher 2 linked the goal explanation of new theory-students practice to several higher goals: relate the introductory activity to the chemical content; make conceptual development explicit and avoid misconceptions; develop routine knowledge (which, in turn contributed via develop flexible knowledge to the core goal develop intellectual skills, ways of thinking). This goal can therefore also be considered a core goal of teacher 2 . Teacher 2 also explicitly planned class discussions that were to contribute to his goal that students also learned from each other in order to deepen their understanding.

The remaining unit goals were assessments of learning outcomes and discussing results. These goals all contributed to teacher 2's core goal that students checked their knowledge. The test also gave him the opportunity to check the learning outcomes and provided the necessary grades.

\section{The Adaptations Teacher 2 Made to the CBC Unit}

Teacher 2 explained that the teacher design team he participated in chose version 2 above version 1 and did not change the main structure of the second version much (Fig. 2). He adopted the new aspects about odors that teacher 1 implemented in his version: orientation on 
the phenomenon of odors goal; the chemistry of odors at the end of the teacher explains and student practice goal; the application task about odors and the cookbook practical on esters. Teacher 2 made only two changes to version 2: he added the study guide goal as he always started a new unit with this goal, and he added an experiment he planned for his students about odors of organic compounds (students have to identify different organic compounds such as alcohol by their smell) in the explain chemical concepts goal.

\section{Using Teacher 2's Goal System as an Explanatory Frame}

For teacher 2, version 2 of the $\mathrm{CBC}$ innovation fit rather well with his usual lesson sequence, which indicates that teacher 2 also prefers the classical way of developing chemical concepts rather than using the context as a guiding principle to select and structure chemical concepts on a need-to-know basis. This can be understood if we look at the goals that teacher 2 connects to his teacher explain and student practice goal, which-similar to teacher 1-unfolds in a classical way (building up knowledge from simple to complex). As we have seen, this goal was connected to several higher goals and therefore was a core goal for teacher 2 (Fig. 4).

The new aspects teacher 2 adopted from version 2 are more difficult to explain in terms of being connected to core goals, but can at least be seen as not conflicting with the core goals he has. The orientation on the phenomenon of odors and perfumes goal can, for example, be seen as a way to elaborate the goal introductory activity which was one of the goals that serves Teacher 1 's core goal students develop a positive learning attitude. The chemistry of odors at the end of his teacher explains, student practice goal was extra, but did not interfere with the classical order in which chemical concepts were developed within this core goal (building up knowledge from simple to complex). The chemistry of esters were usually taught a year later, but was part of the compulsory exams in the Netherlands. The application task about odors can be seen as a task that offered students a chance to check their knowledge (through application-test, a core goal).

Both the practical that teacher 2 developed for version 3 as an addition to the teacher explains and students practice goal, and the practical about esters can be seen as core (do) goals, as teacher 2 connected doing a practical to several higher goals that were core goals, including the core goal students develop a positive learning attitude. Thus leaving out the practical without replacing it with a segment that equally contributes to all the goals teacher 2 connects to a practical, would have undermined all these goals. Finally, teacher 2 added a student guide that also was connected to various different higher goals.

In summary, teacher 2 both adopted new aspects of teaching organic chemistry and modified the sequence in a way that mostly can be seen as serving core goals (at least not interfering with these goals) that were not served in the $\mathrm{CBC}$ unit.

\section{Teacher 3}

\section{Teacher 3's Goal System}

Figure 5 presents Teacher 3's goal system representation for teaching a regular unit. After teacher 3 introduced the unit by means of relate the main topic to the students' daily life experiences in a class discussion (a core "do" goal) and study guide, students were to conduct an experiment that was to focus their attention to phenomena that were to be explained later on. In the regular organic chemistry unit teacher 3, for example, typically started with explaining to the students that the unit was about organic chemistry and that products such 
as gasoline, cosmetics, perfumes, detergents were all examples of organic chemicals. Her goal, she explained, was to relate chemistry to the students' daily lives in order to motivate them and in order to make students see that chemistry was important. Another goal was that students would see relations with previous chemistry topics (another core goal that teacher 3 connected to various other unit goals). To ensure that she achieved this goal she also typically asked them if they knew more examples.

Next, she explained the outline of the unit: what it was about and how the unit was divided in to two parts that both concluded with a test. In the goal students conduct a (or several) introductory experiments and are to answer a guiding question, teacher 3 typically let the students work on experiments that involved phenomena they could not explain yet. Teacher 3 considered this students conduct experiments goal important, because she felt it was important that students do something themselves, a core goal that would motivate students, help them to link the unit to previous chapters (Students see the relation with previous chapters/ consistency), and contribute to anchoring of content through visualization/experience, even if the theory that was needed to explain the observations would be discussed much later (according to Teacher 3).

Teacher 3 used the schoolbook to design the lessons that belonged to the goals, explain new theory and students practice. She connected the goal, students understand and can apply the theoretical knowledge basis and the conceptual structure of the topic at hand [automatized knowledge], to this particular unit goal. They were to apply this knowledge base in a future unit goal: understanding and explaining new, complex phenomena (after the first test). Teacher 3 explained that she was very focused in her teaching on preparing students for the exams, a core goal that she focussed on for a significant part because students want this (Fig. 5). Teacher 3 felt that her students typically worked from "test to test," and wanted to know exactly what they needed to learn for a test: she connected the unit goals explain new theory-students

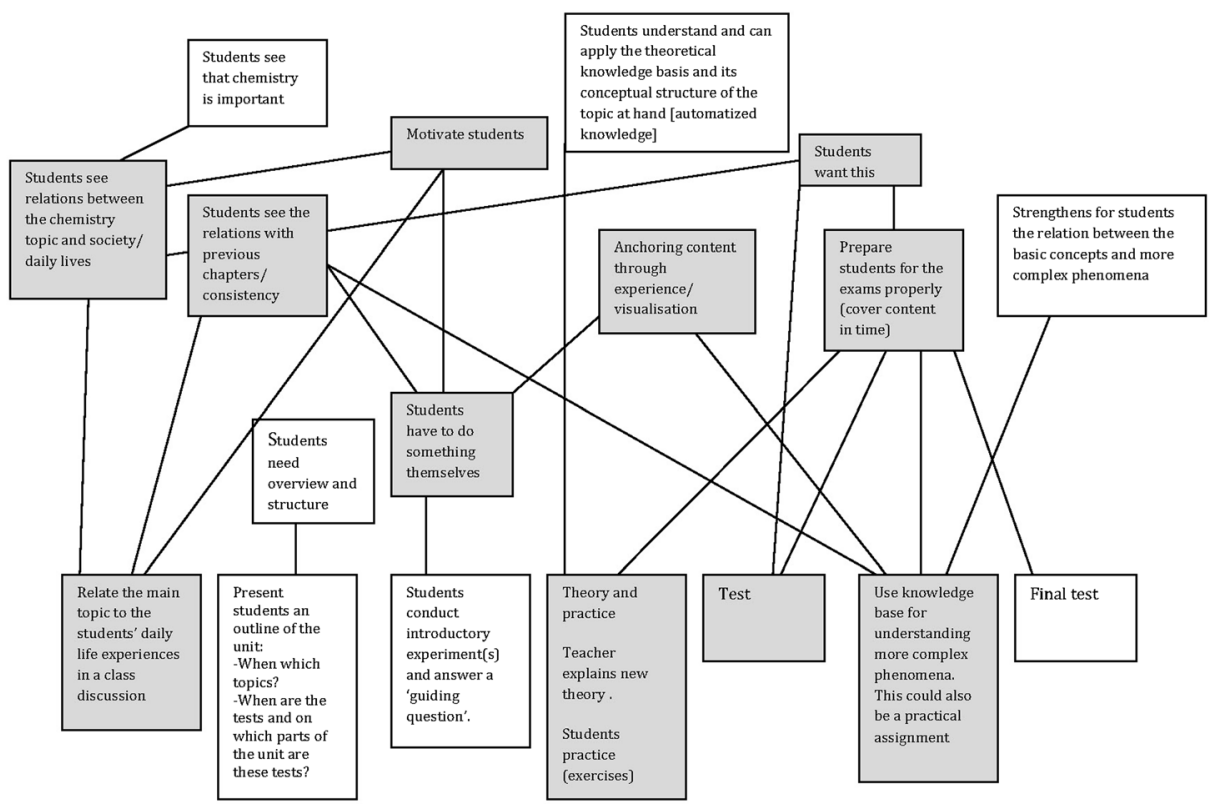

Fig. 5 Teacher 3's goal system of teaching a regular unit. Core goals are marked grey 
practice, use knowledge base for understanding more complex phenomena, pre-test, and final test all to the goal students must be prepared for the final exams.

\section{Adaptations Teacher 3 Made to the CBC Unit}

Teacher 3 decided to only use, after adapting it a bit, the practical teacher 2 and his team developed for the theory and practice part as an introductory experiment, and to teach organic chemistry using her regular method (see Fig. 2). Thus, this practical on smells of organic substances was the only element in version 4 of the unit that still referred to the original context of odors and perfumes. Teacher 3 decided to leave out all the other extra elements about odors and perfumes: orientation on odors and perfumes, the chemistry of odors, the assignment, the practical on esters.

\section{Using Teacher 3's Goal System as an Explanatory Frame}

The decision teacher 3 made to leave out odors and perfumes in the organic chemistry unit, can be explained by means of her core goals. Teacher 3 was very focussed on preparing her students for the tests and the compulsory exams. The goal theory and practice was to contribute to this goal. In designing this goal, she relied heavily on her typically method. Odors and perfumes were not part of her regular methods, the chemistry of esters was usually taught a year later. Hence, leaving odors and perfumes out can be seen as serving her core goal to prepare her students properly for the exams (Fig. 5).

Finally, teacher 3 implemented the experiment designed by teacher 2 as introductory experiment. If we look at Fig. 5, this decision can be explained in terms of core goals: she connected students doing introductory experiments to students do something themselves, a goal she connected to several other higher goals: motivate students; students see relations with previous chapters; anchoring content by visualizing phenomena.

\section{Discussion}

Our aim was to investigate why curriculum slippage occurs and why it is so persistent even if the circumstances are ideal as was the case in this study. We have tried to unpack what mechanisms operate when teachers make decisions about adapting change proposals, using their goal system representations as explanatory frames. Goals system representations show how in the perception of - in this case - the teacher goals mediate between knowledge, beliefs perceptions of context factors and actions in pursuit of a task. Our question was: how can we understand teacher responses to a context-based chemistry unit in terms of serving their core goals? Our results are based on the teacher's self-reports and the materials they used. We did not collect data about actual enactment. In spite of this limitation, we contend that the teacher's perceptions are a valuable information source with respect to decision mechanisms and salient goals that play a role in those mechanisms, particularly as we used the actual materials produced by the respective TDT as a starting point for the interviews.

The results show that for all three teachers the sequence of unit goals of the context-based organic chemistry unit that they said they actually implemented served their core goals especially well, i.e., goals that are connected to more than one other goal. In other words, all three teachers assessed the extent to which the $\mathrm{CBC}$ organic chemistry unit facilitated or 
conflicted with their own core goals and adopted, in a modified form, those elements that served these goals. This was, in fact, a reasonable thing for them to do. Teachers need to attain multiple goals simultaneously, and try to do this in a "good enough" way. The practices that they develop always serve several goals simultaneously. What our results show is that these teachers - even if they agreed with the core principles of the innovation-decided not to implement them as they undermined their core goals.

These findings are consistent with those of an earlier study (Wieringa et al. 2013): teacher goals that have the most connections to other goals determined the extent of and the way the teachers developed context-based biology lessons. Thus, the central interpretive point here is that the teachers decisions primarily reflected deliberate and, importantly, reasonable attempts to serve their core goals in a practical world. From this perspective, slippage is a result of purposeful and reasonable interpretations and decisions in a practical world of teaching (see also Janssen et al. 2014a).

Underlying the theories and methods that we used are assumptions about rationality that fundamentally differ from what is regularly assumed in teacher research (Janssen et al. 2013, 2014a). In most teacher research the implicit assumption, often, is that teachers primarily strive for one goal (optimizing student learning) and that they use the best knowledge available to develop actions in service of that one goal (Wardekker 2000). If teachers do not act in accordance with that one goal, it is generally concluded that they need support to act in a more rational way either by developing the much needed knowledge and skills or by changing the context they work in. Our study shows that teacher behavior can be better understood from the perspective of bounded rationality (Simon 1956; Janssen et al. 2013): in a complex practical world people always strive for multiple goals simultaneously. People lack time, resources and capacity to calculate what actions serve all their goals best. At most, people strive for reasonable goal achievement, and for improvements with respect to the goals they have. Therefore, we can only understand teacher behavior against this background when we know the goals teachers have when making decisions about a teaching task. If a teacher does not act in accordance with a rational innovation proposal we cannot conclude that the teacher acts irrationally. Rather, we can more wisely view this as a sign that we still do not understand a teacher's goals in his/her practical world. Once we know his/her goals almost always the actions of a teacher turn out to be perfectly reasonable.

This does not mean of course that teachers' knowledge, skills, beliefs and work context do not play an important role in explaining teachers' action. However, how teachers will draw upon or develop a need for knowledge and skills all depends on their goals (Schoenfeld 2011). Moreover, teachers share many goals that are derived from demands of the classroom ecology (Doyle and Rosemartin 2012; Kennnedy 2010). In other words, in order to understand teachers' actions we need to know their goals, but knowledge of the classroom context makes many shared goals of teachers understandable. The goal system theory and the derived laddering methodology allowed us to co-construct a teacher's "active" situated goal system and therefore helped us better understand both teacher decision-making and actual teaching practice.

What does this mean for teacher change processes? Although we contend that teachers mostly act in a perfectly reasonable manner, this does not mean that their teaching cannot be improved and that innovation proposals should be rejected all together. What is does mean is that the essential question is not what are deficiencies in teacher knowledge, beliefs and work context and how to fix that, but rather how to forge a connection between teachers' core goals and the lesson or unit goal demands of an innovation. Change emerges from the adaptions that teachers are able and willing to make to their sequence of unit or lesson goals. Of course, innovations, by their very nature, are designed around innovators' goal systems rather than 
specific teachers' goal systems. Thus, for change to happen one should not begin with ways to connect teachers' core goals with the lesson goal demands of a proposed innovation. In several studies we have explored this so called bridging method (Janssen et al. 2013, 2015) and shown this can be done for different innovative approaches to science education (Janssen et al. 2014a, b). Approaches to change that miss this essential step - and in our estimation most approaches do ignore this dynamic - are unlikely to be successful.

Open Access This article is distributed under the terms of the Creative Commons Attribution 4.0 International License (http://creativecommons.org/licenses/by/4.0/), which permits unrestricted use, distribution, and reproduction in any medium, provided you give appropriate credit to the original author(s) and the source, provide a link to the Creative Commons license, and indicate if changes were made.

\section{References}

Abd-El-Khalick, F. (2012). Teaching with and about nature of science, and science teacher knowledge domains. Science \& Education, 22(9), 1-21.

Abell, S. K., \& Lederman, N. G. (2007). Handbook of research on science education. Mahwah: Lawrence Erlbaum Associates, Publishers.

Aikenhead, G. (2003). Review of research on humanistic perspectives in science curricula. Paper presented at the European Science Education Research Association (ESERA) 2003. Conference, Noordwijkerhout, The Netherlands.

Austin, J., \& Vancouver, J. (1996). Goal constructs in psychology: structure, process, and content. Psychological Bulletin, 120(3), 338-375.

Bartos, S. A., \& Lederman, N. G. (2014). Teachers' knowledge structures for nature of science and scientific inquiry: conceptions and classroom practice. Journal of Research in Science Teaching, 51, 1150-1184.

Bennett, J., Lubben, F., \& Hogarth, S. (2007). Bringing science to life: a synthesis of the research evidence on the effects of context-based and STS approaches to science teaching. Science Education, 91(3), 347-370.

Boekaerts, M., Pintrich, P. R., \& Zeidner, M. (2000). Handbook of self-regulated learning. San Diego: Academic.

Borko, H. (2004). Professional development and teacher learning: mapping the terrain. Educational Researcher, $33,3-15$.

Borko, H., Roberts, S. A., \& Shavelson, R. (2008). Teachers' decision making: from Alan J. Bishop to today. In P. Clarkson \& N. Presmeg (Eds.), Critical issues in mathematics education (pp. 37-67). New York: Springer US.

Borko, H., Jacobs, J., \& Koellner, K. (2010). Contemporary approaches to teacher professional development. In E. Baker, B. McGaw, \& P. Peterson (Eds.), International encyclopedia of education (3rd ed.). Oxford: Elsevier.

Carver, C. S. (2012). Self-awareness. In M. R. Leary \& J. P. Tangney (Eds.), Handbook of self and identity (pp. 50-69). New York: The Guilford Press.

Carver, C. S., \& Scheier, M. F. (2011). Self-regulation of action and affect. In K. D. Vohs \& R. F. Baumeister (Eds.). Handbook of self-regulation: research, theory, and applications. Guilford Press.

Charalambous, C. Y., \& Hill, H. C. (2012). Teacher knowledge, curriculum use, and quality of instruction: unpacking a complex relationship. Journal of Curriculum Studies, 44(4), 443-466.

Datnow, A., \& Castellano, M. (2000). Teachers' responses to success for all: how beliefs, experiences and adaptations shape implementation. American Educational Research Journal, 37(3), 775-799.

Davis, E. A., \& Krajcik, J. S. (2005). Designing educative curriculum materials to promote teacher learning. Educational Researcher, 34(3), 3-14.

Deci, E. L., \& Ryan, R. M. (2000). The "what" and "why" of goal pursuits: human needs and the selfdetermination of behavior'. Psychological Inquiry, 11(4), 227-68.

Doyle, W., \& Ponder, G. (1977). The ethic of practicality and teacher decision-making. Interchange, 8, 1-12.

Doyle, W., \& Rosemartin, D. (2012). The ecology of curriculum enactment: frame and tasks narratives. In T. Wubbels, P. den Brok, J. van Tartwijk, \& J. Levy (Eds.), Interpersonal relationships in education: An overview of contemporary research (pp. 137-147). Rotterdam: Sense Publishers.

Driessen, H.P.W., \& Meinema, H.A. (2003). Chemistry between concepts and context, designing for renewal. Enschede, the Netherlands: SLO, Stichting Leerplanontwikkeling. Retrieved from http://www. nieuwescheikunde.nl 
Edelson, D. C. (2001). Learning-for-use: a framework for integrating content and process learning in the design of inquiry activities. Journal of Research in Science Teaching, 38(3), 355-385.

Fishbach, A., \& Ferguson, M. F. (2007). The goal construct in social psychology. In A. W. Kruglanski \& E. T. Higgins (Eds.), Social psychology: handbook of basic principles (2nd ed., pp. 490-515). New York: Guilford Press.

Fishbein, M., \& Ajzen, I. (2010). Predicting and changing behavior. The reasoned action approach. New York: Psychology Press.

Forbes, C. T. (2013). Curriculum-dependent and curriculum-independent factors in preservice elementary teachers' adaptation of science curriculum materials for inquiry-based science. Journal of Science Teacher Education, 24, 179-197. doi:10.1007/s10972-011-9245-0.

Gage, N. L. (2009). A conception of teaching. New York: Springer.

Gilbert, J. K. (2006). On the nature of context in chemical education. International Journal of Science Education, 28(9), 957-976.

Goodlad, J. (1979). Curriculum inquiry: the study of educational practice. New York: McGraw-Hill.

Grunert, K. G., \& Grunert, S. C. (1995). Measuring subjective meaning structures by the laddering method: theoretical considerations and methodological problems. International Journal of Research in Marketing, 12(3), 209-225.

Hofstein, A., \& Lunetta, V. N. (2004). The laboratory in science education: foundations for the twenty-first century. Science Education, 88(1), 28-54.

Janssen, F. J. J. M., Westbroek, H. B., Doyle, W., \& van Driel, J. H. (2013). How to make innovations practical. Teachers College Record, 115(7), 1-43.

Janssen, F. J. J. M., Westbroek, H. B., \& van Driel, J. H. (2014a). How to make guided discovery learning practical for student teachers. Instructional Science, 42(1), 67-90.

Janssen, F. J. J. M., Westbroek, H. B., \& Doyle, W. (2014b). The practical turn in teacher education: designing core practice training sequences. Journal of Teacher Education, 65(3), 195-206.

Janssen, F. J. J. M., Westbroek, H. B., \& Doyle, W. (2015). Practicality studies: how to move from what works in principle to what works in practice. Journal of the Learning Sciences, 24(1), 176-186.

Kennedy, M. M. (2010). Attribution error and the quest for teacher quality. Educational Researcher, 39(8), 591-598.

Kloser, M. (2014). Identifying a core set of science teaching practices: a Delphi expert panel approach. Journal of Research in Science Teaching, 51(9), 1185-1217.

Könings, K. D., Brand-Gruwel, S., \& van Merriënboer, J. J. G. (2005). Towards more powerful learning environments through combining the perspectives of designers, teachers and students. British Journal of Educational Psychology, 75(4), 645-660.

Krajcik, J., Mamlok, R., \& Hug, B. (2001). Learning science through inquiry. In L. Corno (Ed.), Education across a century: the centennial volume (pp. 205-238). Chicago: Chicago University Press.

Kruglanski, A. W., Köpetz, C., Bélanger, J. J., Chun, W. Y., Orehek, E., \& Fishbach, A. (2012). Features of multifinality. Personality and Social Psychology Review, 17(1), 22-39.

Lederman, N. (2007). Nature of science: past, present, and future. In S. Abell \& N. Lederman (Eds.), Handbook of research on science education (pp. 831-879). Mahwah: Lawrence Erlbaum.

Little, J. W. (2002). Locating learning in teachers' communities of practice: opening up problems of analysis in records of everyday practice. Teaching and Teacher Education, 18(8), 917-946.

Little, B. R., \& Travis, G. (2007). The methodology of personal projects analysis: four modules and a funnel. In B. R. Little, S. D. Phillips, \& K. Salmela-Aro (Eds.), Personal project pursuit: goals, action, and human flourishing (pp. 51-93). Mahwahy: Lawrence Erlbaum Associates.

Lord, R. G., Diefendorff, J. M., Schmidt, A. M., \& Hall, R. J. (2010). Self-regulation at work. Annual Review of Psychology, 61, 548-568.

Lumpe, A. T. (2007). Research-based professional development: teachers engaged in professional learning communities. Journal of Science Teacher Education, 18(1), 125-128.

Lyons, T. (2006). Different countries, same science classes: students' experiences of school science in their own words. International Journal of Science Education, 28(6), 591-613.

Mathijsen, I. C. H. (2006). Denken en handelen van docenten [Thinking and acting of teachers]. Utrecht: Utrecht University.

Mcdonald, D. (2003). Curriculum change and the post-modern world: is the school curriculum-reform movement an anachronism? Journal of Curriculum Studies, 35(2), 139-149.

Millar, R., \& Osborne, J. F. (Eds.). (1998). Beyond 2000: science education for the future. London: King's College London.

Naidu, S., Anderson, J., \& Riddle, M. (2000). The virtual print exhibition: a case of learning by designing. In R. Sims, O'Reilly, \& S. Sawkins (Eds.), Learning to choose: choosing to learn (short papers and works in progress) (pp. 109-114). Lismore: Southern Cross University Press. 
Otten, S., \& Soria, V. M. (2014). Relationships between students' learning and their participation during enactment of middle school algebra tasks. The International Journal on Mathematics Education, 46, 815827.

Parchmann, I., Gräsel, P. I., Baer, A., Nentwig, P., Demuth, R., \& Ralle, B. (2006). Chemie im Kontext a symbiotic implementation of a context-based teaching and learning approach. International Journal of Science Education, 28(9), 1041-1062.

Pea, R. D., \& Collins, A. (2008). Learning how to do science education: four waves of reform. In Y. Kali, M. C. Linn, \& J. E. Roseman (Eds.), Designing coherent science education (pp. 3-12). New York: Teachers College Press.

Pedretti, E., \& Nazir, J. (2011). Currents in STSE education: mapping a complex field, 40 years on. Science Education, 95(4), 1-26.

Pintó, R. (2005). Introducing curriculum innovations in science: identifying teachers' transformations and the design of related teacher education. Science Education, 89(1), 1-12.

Pollock, J. L. (2006). Thinking about acting. Logical foundations for rational decision making. Oxford: Oxford University Press.

Prins, G., Bulte, A., Van Driel, J., \& Pilot, A. (2008). Selection of authentic modelling practices as contexts for chemistry education. International Journal of Science Education, 30, 1867-1890.

Remillard, J. T. (2005). Examining key concepts in research on teachers' use of mathematics curricula. Review of Educational Research, 75(2), 211-246.

Remillard, J. T., \& Heck, D. J. (2014). Conceptualizing the curriculum enactment process in mathematics education. ZDM Mathematics Education, 46, 705-718. doi:10.1007/s11858-014-0600-4.

Reynolds, T. J., \& Olson, J. C. (2001). Understanding consumer decision making: the means-end approach to marketing and advertising strategy. Mahway New Jersey: Lawrence Erlbaum Associates.

Roberts, D. A. (1988). What counts as science education? In P. J. Fensham (Ed.), Development and dilemmas in science education (pp. 27-54). London: Routledge Falmer.

Roehrig, G. H., Kruse, R. A., \& Kern, A. (2007). Teacher and school characteristics and their influence on curriculum implementation. Journal of Research in Science Teaching, 44(7), 883-907.

Ryder, J., \& Banner, I. (2013). School teachers' experiences of science curriculum reform. International Journal of Science Education, 35(3), 490-514. doi:10.1080/09500693.2012.665195.

Schoenfeld, A. H. (2011). How we think: a theory of goal-oriented decision making and its educational applications. Taylor \& Francis US. Scho

Shah, J. Y., \& Kruglanski, A. W. (2008). Structural dynamics: the challenge of change in goal systems. In J. W. Shah \& W. L. Gardner (Eds.), Handbook of motivation science (pp. 217-235). New York: Guilford Press.

Simon, H. A. (1956). Rational choice and the structure of the environment. Psychological Review, 63, $129-138$.

Simon, H. A. (1996). The sciences of the artificial (3rd ed.). Cambridge: MIT Press.

Smedslund, J. (2012). What follows from what we all know about human beings. Theory \& Psychology, 22(5), $658-668$.

Solomon, J. (2003). The UK and the movement for science, technology, and society (STS) education. In R. Cross (Ed.), A vision for science education: responding to the work of Peter Fensham (pp. 76-90). New York: Routledge Falmer.

Spillane, J., Reiser, B., \& Reimer, T. (2002). Policy implementation and cognition: reframing and refocusing implementation research. Review of Educational Research, 72(3), 387.

Thomson, D. R., \& Senk, S. L. (2014). The same geometry textbook does not mean the same classroom enactment. Mathematics Education, 46, 781-795.

Tobin, K., \& McRobbie, C. J. (1996). Cultural myths as constraints to the enacted science curriculum. Science Education, 80, 223-241.

Van den Akker, J. (2010). Building bridges: how research may improve curriculum policies and classroom practices. Retrieved from http://www.cidree.org/publications/yearbook_2010

Van Driel, J., \& Berry, A. (2012). Teacher professional development focusing on pedagogical content knowledge. Educational Researcher, 41(1), 26-28.

Van Veen, K., Zwart, R., J. Meirink, J. \& N. Verloop (2010). Professionele ontwikkeling van leraren. Een reviewstudie naar effectieve kenmerken van professionaliseringsinterventies van leraren [professional development of teachers. A review of research on effective characteristics of professional development interventions ]. ICLON/Expertisecentrum Leren van Docenten.

Veledo-de Oliviera, T., Akemi Ikeda, A., \& Cortez Campomar, M. (2006). Discussing laddering application by the means-end chain theory. The Qualitative Report, 11(4), 626-642.

Vohs, K. D., \& Baumeister, R. F. (Eds.) (2011). Handbook of self-regulation: research, theory, and applications. Guilford Press.

Voogt, J., Westbroek, H., Handelzalts, A., Walraven, A., Pieters, J., \& De Vries, B. (2011). Teacher learning in collaborative curriculum design. Teaching and Teacher Education, 27, 1235-1244. 
Vos, M.A.J. (2010). Interaction between teachers and teaching materials. On the implementation of context-based chemistry education. Eindhoven: Technical University of Eindhoven. Unpublished thesis. Retrieved from: http://alexandria.tue.nl/extra2/684861.pdf

Wardekker, W. L. (2000). Criteria for the quality of inquiry. Mind, Culture, and Activity, 7(4), $259-272$. doi:10.1207/S15327884MCA0704_02.

Westbroek, H., Klaassen, K., Bulte, A., \& Pilot, A. (2010). Providing students with a sense of purpose by adapting a professional practice. International Journal of Science Education, 32, 603-627.

Zeidler, D. L., Sadler, T. D., Simmons, M. L., \& Howes, E. V. (2005). Beyond STS: a research-based framework for socioscientific issues education. Science Education, 89(3), 357-377. 